\title{
If you can lose a driving licence, why not a PhD?
} A doctorate is seen as a licence to do science. It should be revocable for misconduct.

Sir - Your Editorial "PhD - club or history?” (Nature 429, 789; 2004), about the withdrawal of Jan Hendrik Schön's doctorate, raises an important point. You argue that a $\mathrm{PhD}$ is a "piece of history" and that by revoking Schön's, as a sanction against fabricating results, the University of Konstanz is treating a $\mathrm{PhD}$ as a mere "club membership".

However, a $\mathrm{PhD}$ is seen by the wider scientific community as a de facto 'licence' to perform science. It is true that some notable scientists, including the late John
Maynard Smith (see Nature 429, 258-59; 2004), have not needed the benefit of a $\mathrm{PhD}$ to carry out excellent science. But holders of the degree are perceived by the general public as being experts in their fields. I would argue that knowingly publishing fraudulent results does far more to diminish the status of a $\mathrm{PhD}$ than selling the bogus doctorates widely available on the Internet "for only US\$35 plus postage".

Although Schön's PhD thesis was found to be free of malpractice, no one would argue that someone passing a driving test flawlessly could not, at some later date, have their licence revoked should their conduct behind the wheel suggest they are no longer a safe and responsible driver. Given the trust that the scientific and non-scientific communities place in a $\mathrm{PhD}$, it is not unreasonable to withdraw one under certain circumstances - rare though I hope these would be.

Adam G. Hart

Department of Animal and Plant Sciences, University of Sheffield, Western Bank,

Sheffield S10 2TN, UK

\section{Species problem solved 100 years ago}

Sir — In his Turning Points essay "Learning from the Altmeister", Axel Meyer highlights the 100th birthday this year of the great evolutionist Ernst Mayr (Nature 428, 897; 2004). Yet the other major centenary for evolutionary biology has been overlooked, both by Meyer and in your anniversary Commentary article "1904 and all that" (Nature 426, 761-764; 2003). Edward Bagnall Poulton's paper "What is a Species?" (Proc. Entomol. Soc. Lond. 1903, lxxvii-cxvi; 1904) was the first to grapple exclusively with the problem of species in an evolutionary framework. Poulton's paper, a version of his January 1904 presidential address to the Entomological Society of London, laid out the research programme for speciation largely adopted today. (See http://abacus.gene.ucl.ac.uk/ jim/Mim/poulton.html.)

I do not wish to belittle the work of Mayr and the geneticist Theodosius Dobzhansky - but our impression that they solved the species problem is illusory. They were merely the ones who translated it from the technical literature, enunciating much more clearly than before what had become the prevailing view of species among those who had thought about the problem.

Both Mayr and Dobzhansky were strongly influenced by Poulton, as well as by Poulton's friend Karl Jordan, also a Fellow of the Entomological Society, and both cited their work. Mayr was to form his views on species and speciation, and particularly the 'biological species concept', nearly 40 years after Poulton's pioneering argument that species were reproductively isolated populations.

Yet the historical links go back even further. In December 1903, shortly before Poulton's lecture, Alfred Russel Wallace gave him a signed book on mimicry and speciation. This contained a reprint of Wallace's 1865 paper on Asian Papilio butterflies: the first to recognize that the female mimics of poisonous swallowtails were members of the same species as non-mimetic males.

Wallace also made the first careful analysis by a darwinist of 'varieties' below the species level, in particular distinguishing geographic races from reproductively isolated species. Darwin had never provided such an analysis, leaving his definition of species vague. Both Poulton and Jordan worked on Papilio butterflies, and cited Wallace's paper.

So, as well as Mayr's 100th birthday, we should celebrate the centenary of Poulton's paper and his gift from Wallace. These events were as epochal in their way for evolutionary biology as was the understanding of the structure of DNA for genetics.

James Mallet

Galton Laboratory, University College London, 4 Stephenson Way, London NW1 2HE, UK

\section{Tight budget should fund benefits, not more posts}

Sir - Your News story "Young biologists rejected as NIH budget squeezes training grants" (Nature 428, 879; 2004) laments the loss of training positions caused by the stagnant training budget at the US National Institutes of Health (NIH).

The desire to hire all deserving candidates is understandable. However, the scientific community must realize that it is in everyone's interest to make sure trainees receive adequate compensation, even if that means fewer positions are funded overall.

The Federation of American Societies for Experimental Biology is concerned that funding restrictions will limit the growth of stipends and benefits for all NIHsupported trainees and fellows.

The NIH Kirschstein-NRSA (National Research Service Award) institutional training grants and individual fellowships are the gold standard for postdoctoral research training in the United States. They identify our most talented and promising young researchers. Despite the prestige of this award, postdoctoral NRSA fellows are not guaranteed access to basic employment benefits. With the median age of postdoctoral fellows rising, these benefits are particularly critical to those who must support families with relatively low salaries and inadequate health and retirement benefits.

The Kirschstein-NRSA programme should put aside extra funds to cover the costs of health and other benefits even if this requires funding fewer slots. This will enhance the stature of the NIH Kirschstein-NRSA programme and strengthen its ability to recruit exceptional research talent.

This much-needed increase in NRSA benefits will send a positive signal to the best and brightest young scientific minds in the United States. We also favour an increase in the NIH training budget, but given the severe budget constraints, it may be necessary to reduce the number of NRSA postdoctoral positions. There is no doubt that this will be a painful decision. However, we cannot afford to compromise the programme by penalizing these outstanding young scientists.

\section{Robert D. Wells}

Federation of American Societies for Experimental Biology, 9650 Rockville Pike, Bethesda,

Maryland 20814, USA

\section{correspondence}

Contributions to Correspondence may be submitted to corres@nature.com. They should be no longer than 500 words, and ideally shorter. Published contributions are edited. 